\title{
Variação sazonal e temporal da qualidade das águas em um ponto do Córrego Gameleiras usando técnicas quimiométricas robustas
}

\author{
Seasonal and temporal variation in water quality from one \\ point at Gameleiras' stream using robust chemometric techniques
}

Claudia Vilhena Schayer Sabino', Ludmila Vieira Lage ${ }^{2}$, César Vinícius de Noronha ${ }^{3}$

\begin{abstract}
RESUMO
O córrego Gameleiras é afluente do reservatório de Volta Grande e tem sido afetado pela eutrofização e "bloom" de algas, devido ao aumento das taxas de fósforo e outros contaminadores, recebidos via seus tributários. Esta pesquisa teve como objetivo avaliar a variação sazonal e temporal da qualidade das águas em um ponto de coleta do córrego, próximo ao reservatório, no período de 1998 a 2014. Foram utilizadas técnicas estatísticas robustas, como análise de agrupamento e séries temporais.
\end{abstract}

Palavras-chave: quimiometria robusta; modelos SARIMA; qualidade das águas; córrego Gameleiras.

\begin{abstract}
Gameleiras' stream is a tributary of the Volta Grande reservoir and has been affected by eutrophication and "bloom" of algae due to increased phosphorus rates and other contaminants received via its tributaries. This research aimed at evaluating the seasonal and temporal variation of water quality at a spot at the stream, near the reservoir, from 1998 to 2014. Robust statistical techniques, such as cluster analysis and time series, were employed.
\end{abstract}

Keywords: chemometrics robust; SARIMA models; water quality; Gameleiras' stream.

\section{INTRODUÇÃO}

A degradação e a poluição das águas constituem, atualmente, grandes problemas devido aos impactos negativos sobre os ecossistemas, a saúde tanto do planeta quanto das pessoas e a economia. Essas questões podem resultar de fatores naturais e/ou ações antrópicas, sendo a urbanização, a pecuária e a irrigação as mais significativas. $\mathrm{O}$ antropismo, escola de pensamento filosófico que consiste no estudo dos princípios que consideram o homem contrário a toda natureza, pode ser utilizado na explicação das causas da eutrofização (PACHECO, 2009).

A eutrofização é o fenômeno em que o ecossistema aquático é enriquecido por nutrientes diversos, principalmente compostos nitrogenados e fosforados. O aumento da disponibilidade de nutrientes é um dos principais impactos qualitativos e quantitativos em rios, lagos e reservatórios.

As principais ações causadoras da eutrofização artificial são as entradas de águas residuárias domésticas e industriais, a drenagem artificial, as contribuições de fertilizantes utilizados na agricultura, a erosão do solo e o uso de detergentes não biodegradáveis (TUNDISI; MATSUMURA-TUNDISI; TUNDISI, 2008). Uma das consequências desse processo é o crescimento excessivo de seres vivos, entre eles as cianobactérias, os mexilhões dourados e as macrófitas aquáticas, o que gera sérios agravos ambientais e impactos negativos à saúde do ecossistema aquático.

O ponto de coleta BG057, utilizado no estudo, é monitorado pelo Instituto Mineiro de Gestão das Águas (IGAM) e está localizado no córrego Gameleiras.

O córrego Gameleiras é efluente do reservatório de Volta Grande e está situado na porção sul do município de Uberaba, próximo à margem do Rio Grande, divisa dos Estados de Minas Gerais e São Paulo. A Usina Hidrelétrica de Volta Grande começou a ser operada no ano de 1974, e seu reservatório tem volume útil de $268,00 \mathrm{hm}^{3}$, estendendo-se por uma área de 196,68 km², com altura máxima de $49 \mathrm{~m}$. O córrego $\square$

'Doutora pela Universidade Federal de Minas Gerais (UFMG). Professora Adjunta no Programa de Pós-Graduação em Ensino de Ciências e Matemática da Pontifícia Universidade Católica de Minas Gerais (PUC Minas) - Belo Horizonte (MG), Brasil.

²Bacharela em Estatística pela UFMG. Assistente de Pesquisa no Programa de Pós-Graduação em Ensino de Ciências e Matemática da PUC Minas - Belo Horizonte (MG), Brasil. ${ }^{3}$ Doutorando pela PUC Minas - Belo Horizonte (MG), Brasil.

Endereço para correspondência: Claudia Vilhena Schayer Sabino - Avenida Dom José Gaspar, 500 - Coração Eucarístico - 30535-901 - Belo Horizonte (MG), Brasil E-mail:sabinoc@pucminas.br

Recebido: 12/01/16 - Aceito: 06/09/16 - Reg. ABES: 158455 
está inserido na área do Distrito Industrial III de Uberaba e localizado a aproximadamente $20 \mathrm{~km}$ do centro urbano do município. $\mathrm{O}$ distrito abrange indústrias químicas, de fertilizantes, de distribuição de combustíveis e transportadoras (UBERABA, 2014).

O reservatório de Volta Grande é um exemplo de ambiente que passa por eutrofização e "bloom" de algas devido ao aumento das taxas de fósforo que vem recebendo via seus tributários. Ainda assim, a Companhia Energética de Minas Gerais (CEMIG), concessionária da hidrelétrica, com a aplicação de uma série de medidas técnicas de tratamento da água na região, tem conseguido minimizar os impactos ambientais e promover melhora nas condições da qualidade da água (CARVALHO \& ROLLA, 2008).

O fósforo é um dos contaminadores mais críticos na região. As principais fontes são os esgotos, a agropecuária e os efluentes industriais, inclusive de uma fábrica de fertilizantes nas margens do reservatório. Entre os episódios que ocorreram em Volta Grande, destacam-se o "bloom" de algas nos anos de 1999, 2004 e 2005 e a morte de peixes em 2001 (CARVALHO \& ROLLA, 2008).

Esta pesquisa teve como objetivo avaliar estatisticamente a variação sazonal e temporal da qualidade das águas do córrego Gameleiras no ponto de monitoramento BG057, fazendo associação entre usos e ocupações do solo na região.

\section{METODOLOGIA}

O estudo levou em consideração os dados da Estação de Amostragem BG057, disponibilizados pelo IGAM, entre os anos 1998 e 2014 (INFOHIDRO, 2015). O ponto de coleta BG057 está localizado no córrego Gameleiras, coordenadas geográficas $20^{\circ} 00^{\prime} 50,00^{\prime \prime}$ latitude sul e 4752'52,00" longitude oeste.

A primeira etapa da investigação estatística foi avaliar as desconformidades dos resultados das análises de água do BG057 em relação aos valores estabelecidos na Deliberação Normativa no 01/08 (DN 01/08), do Conselho Estadual de Política Ambiental/Conselho Estadual de Recursos Hídricos (COPAM/CERH) (MINAS GERAIS, 2008). A DN 01/08 fixa padrões de qualidade a serem respeitados e impõe ao poder público o dever de fiscalizar o atendimento aos limites de qualidade estabelecidos. As águas do córrego Gameleiras são enquadradas como Classe II.

O teste de Shapiro-Wilk (SHAPIRO \& WILK, 1965), a 5\% de significância, foi aplicado aos dados de cada variável para verificar se eram ou não provenientes de uma população com distribuição normal. As variáveis e coletas com $20 \%$ ou mais de dados censurados (abaixo do limite de quantificação do método analítico) e/ou vazios (não analisadas) foram excluídas (REIMANN et al., 2008). Variáveis com valor de desvio absoluto mediano (MAD) igual a zero também foram excluídas, pois apresentam baixa variabilidade e interferem nas análises estatísticas multivariadas.
O cálculo do MAD é dado pela Equação 1:

$\mathrm{MAD}=1,4826$ mediana $\left(\left|\mathrm{x}_{\mathrm{i}}-\operatorname{mediana}\left(\mathrm{x}_{\mathrm{i}}\right)\right|\right)$

Em que:

$x_{i}$ é o valor da variável " $x$ " na coleta "i".

A presença de outliers pode afetar gravemente os resultados finais da análise estatística. Assim, foi feita uma comparação multivariada entre a distância Mahalanobis e a distância robusta (TODOROV \& FILZMOSER, 2009).

Grande parte dos dados ambientais é composicional, característica que pode gerar imprecisões nos cálculos estatísticos. Logo, cada valor do banco de dados foi dividido pela mediana da respectiva variável, com o objetivo de igualar as unidades, e, em seguida, foi feita a transformação centered log-ratio (clr), com o intuito de evitar as imprecisões (REIMANN et al., 2008; TODOROV \& FILZMOSER, 2009).

A análise de agrupamento é uma técnica multivariada hierárquica aglomerativa, com estrutura do tipo árvore, cujo resultado apresenta máxima homogeneidade de objetos dentro de grupos e, ao mesmo tempo, máxima heterogeneidade entre os grupos (RONG, 2011). O objetivo da aplicação da técnica foi selecionar as variáveis que seriam utilizadas no estudo de séries temporais.

A modelagem estatística por séries temporais foi utilizada com dois intuitos: validar a metodologia proposta e verificar tendências e prever o comportamento futuro da qualidade das águas no trecho estudado do córrego Gameleiras.

Para o estudo, foi utilizado o modelo sazonal autorregressivo integrado de média móvel (SARIMA), também conhecido por Modelo de Box-Jenkins (BOX; JENKINS; REINSEL, 2008). Na etapa de identificação e estimação dos parâmetros do modelo (COGHLAN, 2014), foram avaliadas graficamente a função de autocorrelação total (FAC) e a função de autocorrelação parcial (FACP). A verificação da adequabilidade do modelo (MORETTIN \& TOLOI, 2006) constituiu a análise de resíduos, sendo feitos os testes de Normalidade e Ljung-Box.

Foi escolhido para fazer previsão o modelo que atendeu aos requisitos dos testes e que apresentou os menores critérios de decisão (COGHLAN, 2014). A validação da previsão das variáveis por séries temporais deu-se utilizando os dados de temperatura máxima do ar, disponíveis no site do Instituto Nacional de Meteorologia (INMET, 2015).

O teste não paramétrico Wilcoxon (SHESKIN, 2011) foi utilizado para comparar a distribuição real de temperatura com a prevista. Já o teste Kruskal-Wallis (SHESKIN, 2011), também não paramétrico, verificou se há diferença estatística entre as coletas trimestrais e os diferentes anos de monitoramento. Foi adotado para os testes o nível de $5 \%$ de significância. 
Para os estudos estatísticos, foram utilizados o software R (R CORE TEAM, 2015) e os pacotes StatDA (FILZMOSER, 2015), rrcov (TODOROV, 2013), aTSA (QIU, 2015), forecast (HYNDMAN, 2015) e tseries (TRAPLETTI, 2015).

A caracterização do uso e da ocupação do solo no córrego Gameleiras foi desenvolvida com base no trabalho de campo realizado por meio do Projeto GT399, da Pontifícia Universidade Católica de Minas Gerais, em conjunto com a CEMIG. Na pesquisa de campo, foram observados os impactos causados pelas atividades econômicas inseridas próximo ao curso d'água em estudo.

\section{RESULTADOS E DISCUSSÃO}

\section{Comparação entre os resultados e os limites estabelecidos na lei}

As concentrações do fósforo total e do oxigênio dissolvido ultrapassaram os limites estabelecidos pela legislação DN 01/08 em 100\% das coletas. Os valores de fósforo no córrego Gameleiras estão entre os maiores registros no Estado de Minas Gerais e associam-se, principalmente, aos efluentes de indústrias de fertilizantes da região. $\mathrm{O}$ fato de o córrego afluir para a represa de Volta Grande potencializa o processo de eutrofização nesse ambiente (IGAM, 2010). Em decorrência desse aporte, a matéria orgânica é degradada no trecho em estudo, com consequente consumo de oxigênio dissolvido e diminuição do $\mathrm{pH}$.

O ferro dissolvido e o manganês total apresentaram 92 e $69 \%$ de desconformidade, respectivamente. Esses metais são constituintes naturais do solo da região e, no córrego Gameleiras, sua presença pode ser justificada pelo revolvimento do sedimento no processo de extração de areia, além do cultivo de cana-de-açúcar no município de Uberaba. Os valores de ferro acima dos limites da legislação podem ainda dever-se aos efluentes de indústrias de fertilizantes (CASTILLO et al., 2012). A presença da alta concentração de manganês pode ser também influência das atividades mineradoras da região (IGAM, 2010).

O pH ter aparecido mais ácido em $49 \%$ das coletas deve-se principalmente aos efluentes industriais, assim como às violações de cianeto livre (36\%), provavelmente advindas de lançamentos de efluentes das fecularias das fazendas da região.

A presença de óleos e graxas em 19\% das amostragens pode estar associada ao esgoto doméstico das residências da região, aliado à presença de dragas na extração de areia deste córrego.

Também ultrapassaram os limites da DN 01/08 as análises de coliformes termotolerantes (17\%), sulfeto (6\%), alumínio dissolvido (5\%), chumbo total (5\%), demanda bioquímica de oxigênio (4\%), mercúrio (2\%), fenóis totais (2\%) e cádmio (1\%).

\section{Pré-tratamento estatístico dos dados}

O teste de Shapiro-Wilk mostrou que nenhuma das 55 variáveis que compunham inicialmente o banco de dados apresentou distribuição normal. O estudo de outliers detectou valores anômalos no início do monitoramento, entre os anos de 1998 e 2000 . Tendo em vista não ser possível a rastreabilidade de tais resultados, as coletas foram descartadas. A variável de demanda bioquímica de oxigênio apresentou MAD igual a zero e foi eliminada, pois suas concentrações ficaram próximas ao limite mínimo de quantificação do método analítico em todo o período de estudo.

Após a aplicação dos critérios estatísticos descritos na metodologia, o banco de dados ficou composto por 16 variáveis: cloreto $(\mathrm{Cl})$, coliformes termotolerantes (Colitermo), coliformes totais (ColiT), ferro $(\mathrm{Fe})$, fósforo total $(\mathrm{P})$, manganês total $(\mathrm{Mn})$, nitrogênio amoniacal total (NAT), nitrato, oxigênio dissolvido (OD), $\mathrm{pH}$, sólidos dissolvidos totais (SDT), sólidos em suspensão totais (SST), sólidos totais (ST), temperatura do ar (Tar), temperatura da água (Tagua) e turbidez. A estatística descritiva das diferentes variáveis está apresentada na Tabela 1 .

\section{Análise de agrupamento}

O resultado do dendograma (Figura 1) apontou cinco grupos principais. O primeiro grupo pode ser relacionado prioritariamente ao esgoto, o segundo à agropecuária, o terceiro grupo às atividades antrópicas como mineração, enquanto o quarto grupo pode refletir os impactos do lançamento de efluentes industriais. O quinto grupo tem semelhança às características do segundo e quarto grupos, ou seja, pode ser associado tanto à agropecuária quanto aos impactos do lançamento de efluentes industriais.

O estudo de séries temporais foi realizado para a variável que apresentou maior percentagem de coletas em desconformidade com os limites da legislação de cada grupo; portanto, coliformes termotolerantes, oxigênio dissolvido, ferro, $\mathrm{pH}$ e fósforo.

\section{Validação da metodologia de séries temporais}

Para os cálculos de validação, os dados de temperatura máxima do ar foram utilizados: o período 1998 a 2012 foi considerado como "avaliado", e os anos 2013 e 2014 como base para "previsão". A série temporal da temperatura do ar, segundo o teste Dickey-Fuller (ADF), era estacionária $(p=0,07)$ e apresentou comportamento sazonal ao longo dos anos.

O modelo que obteve o melhor ajuste à distribuição dos dados de temperatura máxima do ar foi o SARIMA $(1,1,1)(3,0,2){ }_{4}$. Os testes de adequabilidade do modelo apontaram que ele era aceitável para dados ambientais. Por último, o teste não paramétrico Wilcoxon comparou a distribuição real da temperatura máxima do ar de 2013 e 2014 e a prevista para os mesmos anos, concluindo que elas eram estatisticamente iguais $(\mathrm{p}=0,804)$. Assim, a metodologia proposta foi considerada válida 
para ser aplicada no estudo temporal e sazonal das variáveis selecionadas na análise multivariada de agrupamento.

\section{Coliformes termotolerantes}

As bactérias do grupo coliformes, originadas do trato intestinal humano e de outros animais, são alguns dos principais indicadores de contaminações fecais na água. A determinação dos valores de coliformes assume importância como parâmetro indicativo da possibilidade de existência de microrganismos patogênicos, responsáveis pela transmissão de doenças de veiculação hídrica, tais como febre tifoide, febre paratifoide, disenteria bacilar e cólera (IGAM, 2010).

O valor mediano da variável na região foi de $140 \mathrm{NMP} .100 \mathrm{~mL}^{-1}$ (MAD: 160 NMP.100 mL $\mathrm{mL}^{-1}$ ). Considerando que modelos de previsão ARIMA necessitam que a série seja estacionária, aplicou-se o teste ADF para verificar esse requisito. Uma vez constatada a não estacionaridade da série $(\mathrm{p}=0,008)$, foi realizada a primeira diferença $(\mathrm{p}=0,046)$, que obteve êxito. O cálculo das séries temporais foi então feito com a primeira ordem de integração. O modelo mais bem ajustado à série de

Tabela 1 - Estatística descritiva das variáveis consideradas.

\begin{tabular}{|c|c|c|c|c|c|c|c|c|c|}
\hline Variável & Unidade & Mínimo & Mediana & Média & Máximo & $\begin{array}{l}\text { Desvio- } \\
\text { padrão }\end{array}$ & MAD & $\begin{array}{c}\text { Coeficiente de } \\
\text { variação (\%) }\end{array}$ & $\begin{array}{l}\text { Coeficiente } \\
\text { de variação } \\
\text { robusto (\%) }\end{array}$ \\
\hline $\mathrm{Cl}$ & $\mathrm{mg} / \mathrm{L}$ & 2,63 & 10,78 & 12,41 & 32 & 6,203 & 6,049 & 49,97 & 56,09 \\
\hline ColiT & NMP.100mL-1 & 1 & 1300 & 5670 & 160000 & 20090 & 1483 & 354,4 & 114 \\
\hline Colitermo & NMP.100mL-11 & 1 & 135 & 1404 & 30000 & 3991 & 166,1 & 284,2 & 123 \\
\hline $\mathrm{Mn}$ & $\mathrm{mg} / \mathrm{L}$ & 0,004 & 0,194 & 0,3065 & 1,816 & 0,3378 & 0,1987 & 110,2 & 102,4 \\
\hline NAT & $\mathrm{mg} / \mathrm{L}$ & 0,05 & 0,1 & 0,2939 & 4,2 & 0,5911 & 0,07413 & 201,2 & 74,13 \\
\hline OD & $\mathrm{mg} / \mathrm{L}$ & 0,3 & 1,1 & 1,227 & 4,1 & 0,7663 & 0,593 & 62,45 & 53,91 \\
\hline$P$ & $\mathrm{mg} / \mathrm{L}$ & 0,21 & 1,325 & 2,071 & 9,24 & 1,905 & 0,9785 & 91,99 & 73,85 \\
\hline ST & $\mathrm{mg} / \mathrm{L}$ & 54 & 113,5 & 128,1 & 334 & 52,47 & 51,89 & 40,97 & 45,72 \\
\hline Tagua & ${ }^{\circ} \mathrm{C}$ & 18 & 23,95 & 23,51 & 28 & 2,517 & 2,52 & 10,7 & 10,52 \\
\hline Tar & ${ }^{\circ} \mathrm{C}$ & 17,4 & 27,6 & 26,96 & 34 & 4,087 & 5,041 & 15,16 & 18,26 \\
\hline Turbidez & Turbidez & 1,74 & 4,825 & 6,154 & 21,4 & 4,161 & 2,839 & 67,6 & 58,84 \\
\hline
\end{tabular}

MAD: desvio absoluto mediano; Cl: cloreto; Colitermo: coliformes termotolerantes; ColiT: coliformes totais; Fe: ferro; P: fósforo total; Mn: manganês total; NAT: nitrogênio amoniacal total; OD: oxigênio dissolvido; sólidos dissolvidos totais (SDT); SST: sólidos em suspensão totais; ST: sólidos totais; Tar: temperatura do ar; Tagua: temperatura da água.

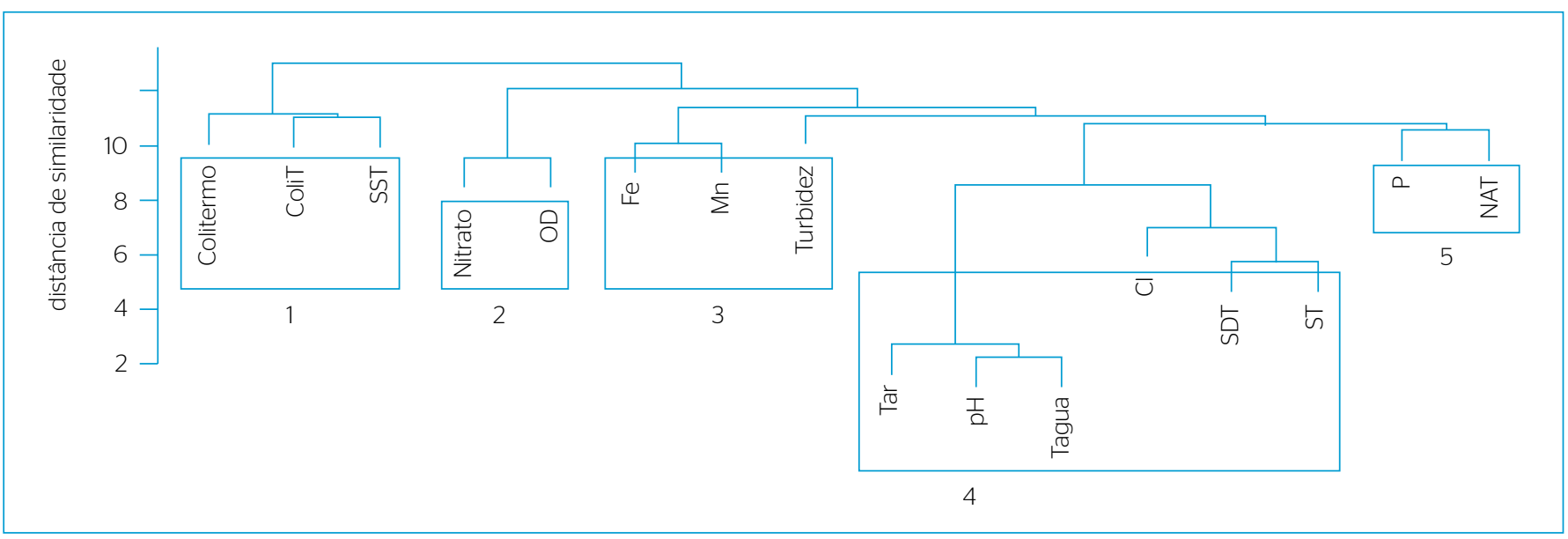

Figura 1 - Agrupamento hierárquico das variáveis. 
coliformes foi o SARIMA $(3,0,0)(1,0,0)$, e o diagnóstico dos resíduos (Figura 2) apontou adequabilidade, ainda que no gráfico Q-Q alguns pontos tenham ficado com pequeno afastamento da reta.

A Figura 3 apresenta a distribuição dos valores de Colitermo ao longo dos anos e, em vermelho, a previsão para os próximos dois. Foi percebido que a maior frequência de resultados acima do Valor Máximo Permitido na lei (VMP), 1.000 NMP.100 mL ${ }^{-1}$, ocorreu no período de expansão da cana-de-açúcar. A previsão realizada para a série de coliformes não apontou uma melhora na qualidade das águas.

O teste Kruskal-Wallis, aplicado à distribuição da variável estudada, indicou que os resultados de coliformes variaram significativamente, do ponto de vista estatístico, ao longo dos anos $(\mathrm{p}=0,011)$. A Figura 4 confirma a tendência de piora da qualidade das águas, mais acentuadamente nos últimos dois anos.

\section{Oxigênio dissolvido}

O oxigênio dissolvido é essencial para a manutenção de processos de autodepuração em sistemas aquáticos naturais e estações de tratamento de esgotos. Durante a estabilização da matéria orgânica, as bactérias fazem uso do oxigênio em seus processos respiratórios, podendo causar

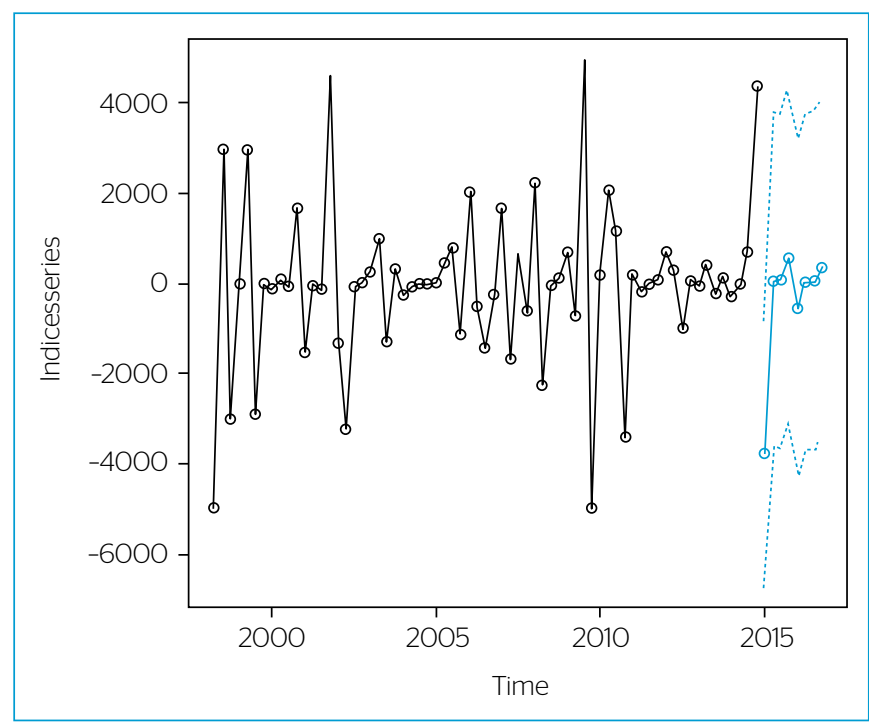

Figura 3 - Previsão pelo método de séries temporais.

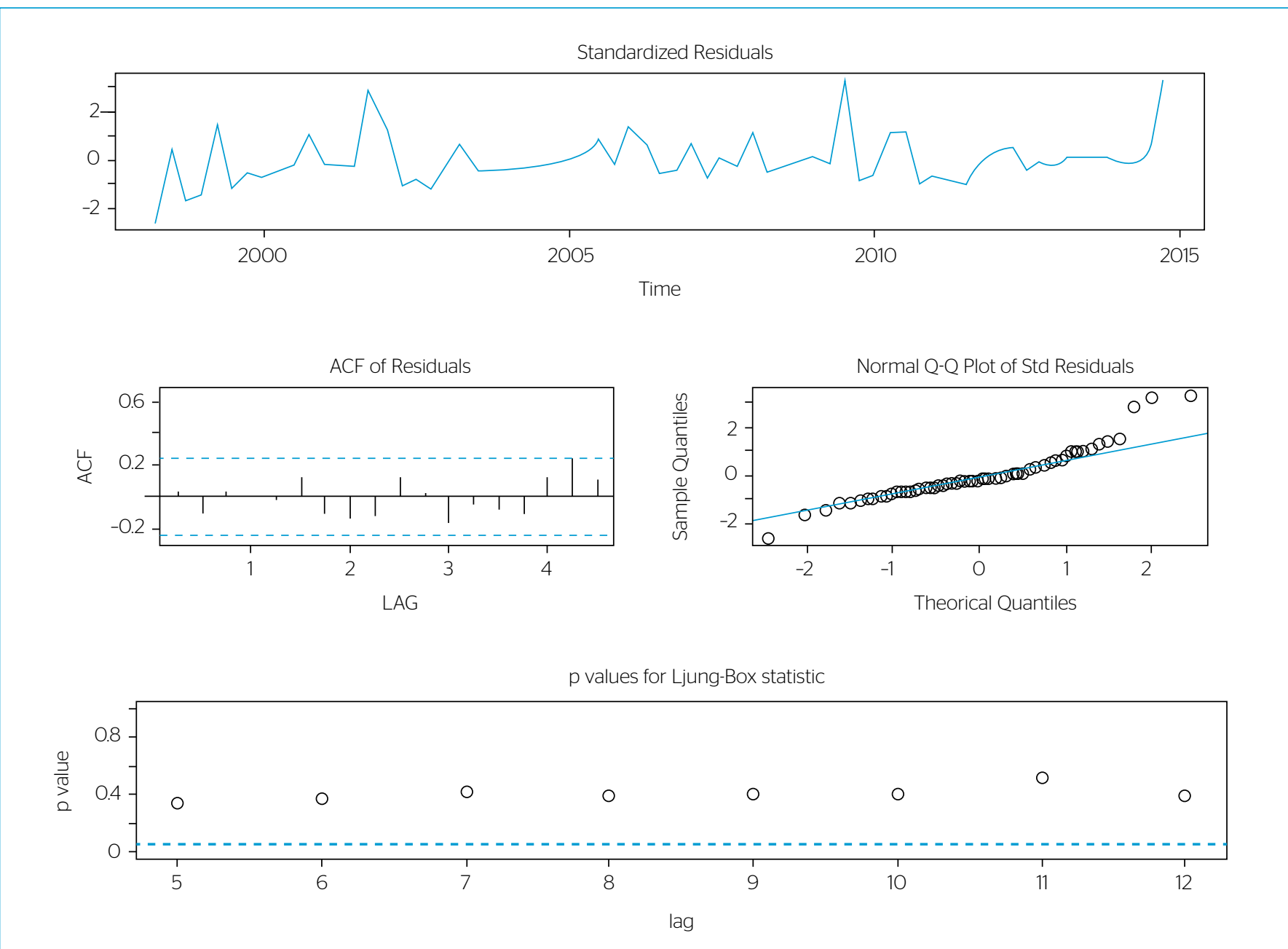

Figura 2 - Validação do modelo de coliformes termotolerantes - modelo sazonal autorregressivo integrado de média móvel $(3,0,0)(1,0,0)$. 
uma redução de sua concentração no meio (ESTEVES, 2011). Por meio da medição do teor de OD, os efeitos de resíduos oxidáveis sobre águas

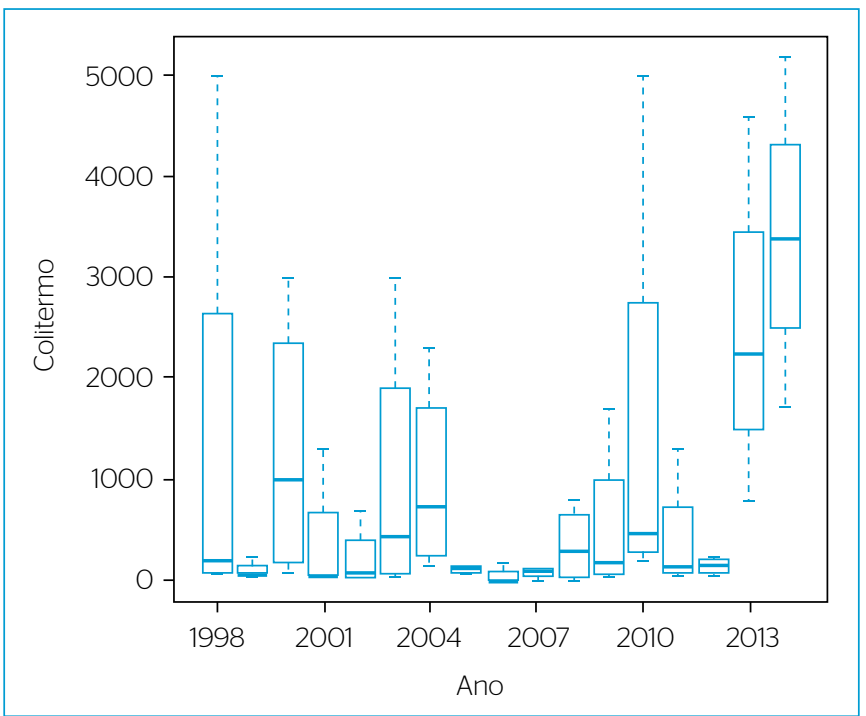

Figura 4 - Boxplot dos valores de coliformes em cada ano de coleta. receptoras e a eficiência do tratamento dos esgotos durante a oxidação bioquímica podem ser avaliados. Os níveis de OD também indicam a capacidade de um corpo de água natural em manter a vida aquática (CETESB, 2015). No BG057, a concentração mediana de OD foi igual a $1 \mathrm{mg} . \mathrm{L}^{-1}$ e variou, segundo o MAD, $\pm 0,6 \mathrm{mg} . \mathrm{L}^{-1}$. O limite mínimo definido na DN 01/08 é $5 \mathrm{mg} . \mathrm{L}^{-1}$, e em todas as coletas realizadas foram encontrados valores inferiores.

A série dos resultados do $\mathrm{OD}$, segundo o teste $\mathrm{ADF}$, não era estacionária $(\mathrm{p}=0,3057)$, mas após a primeira diferença aplicada, tornou-se assim ( $p=0,006)$. O modelo sugerido para a série integrada de ordem 1 do OD foi SARIMA $(0,0,1)(0,1,1)_{4}$. O diagnóstico dos resíduos do modelo está apresentado na Figura 5 e, apesar de alguns afastamentos nas caudas, foi possível verificar que eles eram adequados aos dados para a realização das previsões.

A distribuição do OD ao longo dos anos e a previsão para os próximos dois, em vermelho, está apresentada na Figura 6. Foi notada uma tendência de redução do OD em 1998 e 1999, com melhora a partir de 2000 até 2006 devido, provavelmente, à redução do rebanho bovino e da plantação de grãos e algodão. A partir de 2006, a qualidade das

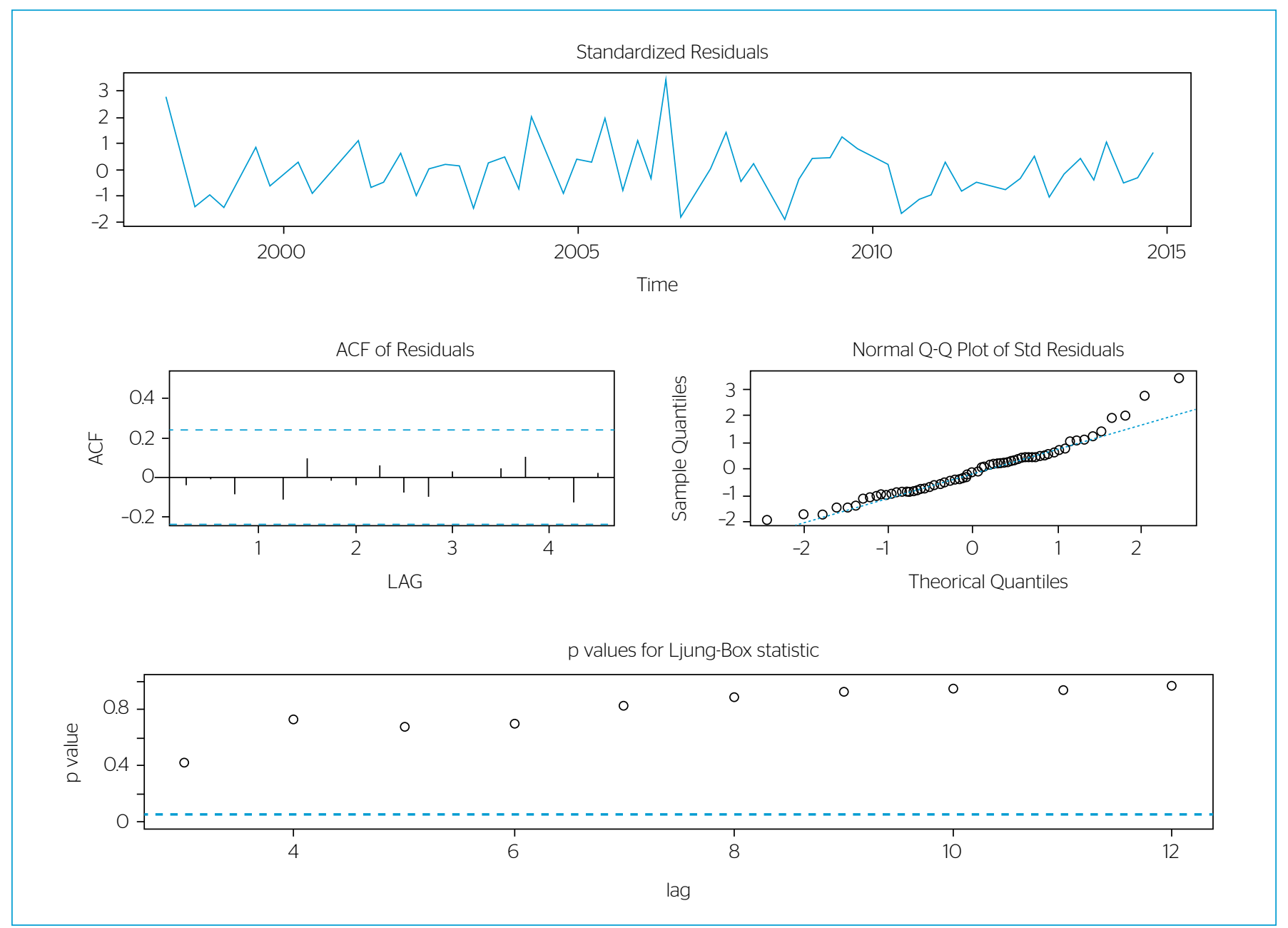

Figura 5 - Validação do modelo de oxigênio dissolvido - modelo sazonal autorregressivo integrado de média móvel $(0,0,1)(0,1,1)$. 
águas piorou devido à expansão da cultura da cana-de-açúcar. A previsão indicou piora na qualidade das águas.

É possível afirmar, por meio do teste Kruskal-Wallis, que as concentrações de OD variaram com o trimestre $(=0,004)$, mas não com o ano $(=0,22)$. A Figura 7 apresenta o boxplot dos resultados de OD por trimestre e permitiu concluir que a qualidade das águas é sempre melhor no período de seca (março a outubro) devido a menor lixiviação.

\section{Ferro}

O ferro é um micronutriente indispensável aos seres vivos (ESTEVES, 2011). Aparece, normalmente, da dissolução de compostos do solo e dos despejos industriais (IGAM, 2010). Em épocas de alta precipitação, o nível de ferro na água aumenta em decorrência dos processos de erosão nas margens dos corpos d'água. Nas indústrias metalúrgicas, o ferro é disponibilizado por meio da decapagem, que consiste na remoção da camada oxidada das peças antes de seu uso. Em quantidade adequada, esse metal é essencial ao sistema bioquímico das águas, podendo, em grandes quantidades, tornar-se nocivo, dando sabor e cor desagradáveis à água, além de elevar a sua dureza, tornando-a inadequada para uso doméstico e industrial (BRAGA \& HESPANHOL, 2005).

O VMP, segundo a legislação, é $0,3 \mathrm{mg} . \mathrm{L}^{-1}$ mas, na região, o valor mediano de ferro foi igual a $0,7 \pm 0,5 \mathrm{mg} \cdot \mathrm{L}^{-1}$. Esse elemento é constituinte natural do solo da região e sua presença em valores acima do permitido pode ser explicada pela extração de areia na região, que é mais intensa durante a seca.

O teste $\mathrm{ADF}$ foi aplicado e confirmou a estacionaridade da variável em estudo ( $\mathrm{p}=0,001)$. De acordo com os modelos testados, o que

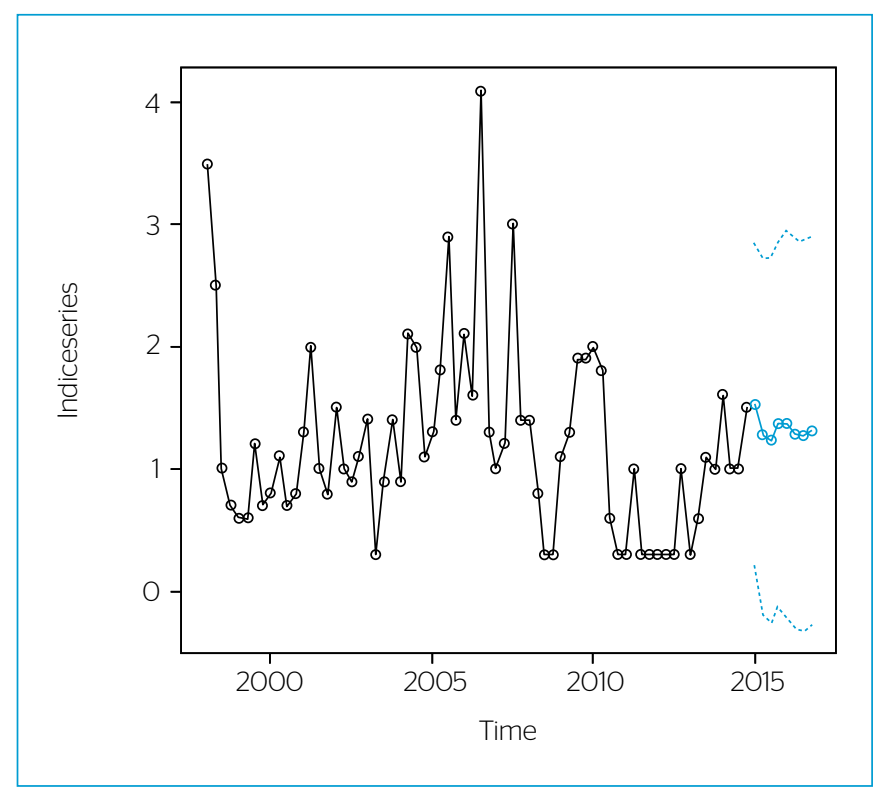

Figura 6 - Previsão pelo método de séries temporais. mais se ajustou em termos de significância estatística foi o SARIMA $(0,0,1)(0,1,1)_{4}$. A validação, feita por meio do diagnóstico dos resíduos (Figura 8), mostrou que o modelo é adequado para a realização das previsões.

A série de ferro e previsão para os próximos dois anos (Figura 9) indicou que não houve melhora ou perspectivas de melhora na qualidade das águas ao longo do período de estudo.

O teste Kruskal-Wallis, aplicado à distribuição de ferro, apresentou diferença estatisticamente significativa entre os trimestres $(p=0,000)$, mas não entre os anos de monitoramento $(\mathrm{p}=0,562)$. A Figura 10 mostra o boxplot dos resultados por trimestre e é possível concluir que a concentração de ferro aumenta a partir de março. Isso é esperado, uma vez que a extração de areia só é feita na seca. $\mathrm{O}$ valor aumenta a partir do início da seca até as primeiras chuvas, quando começa a diminuir para aumentar novamente no ano seguinte.

\section{$\mathrm{pH}$}

O pH define o caráter ácido, básico ou neutro de uma solução aquosa. Sua origem natural está associada à dissolução de rochas, à absorção de gases da atmosfera, à oxidação da matéria orgânica e à fotossíntese, enquanto sua origem antropogênica está relacionada aos despejos domésticos e industriais (IGAM, 2010). Os organismos aquáticos estão geralmente adaptados às condições de neutralidade; em consequência, alterações bruscas do $\mathrm{pH}$ da água afetam as taxas de crescimento de microrganismos e podem resultar no desaparecimento dos organismos presentes no ecossistema (ESTEVES, 2011).

Os valores fora das faixas recomendadas pela legislação (entre 6 e 9) podem alterar o sabor da água e contribuir para a corrosão do sistema de distribuição de água, ocorrendo, assim, uma possível extração do

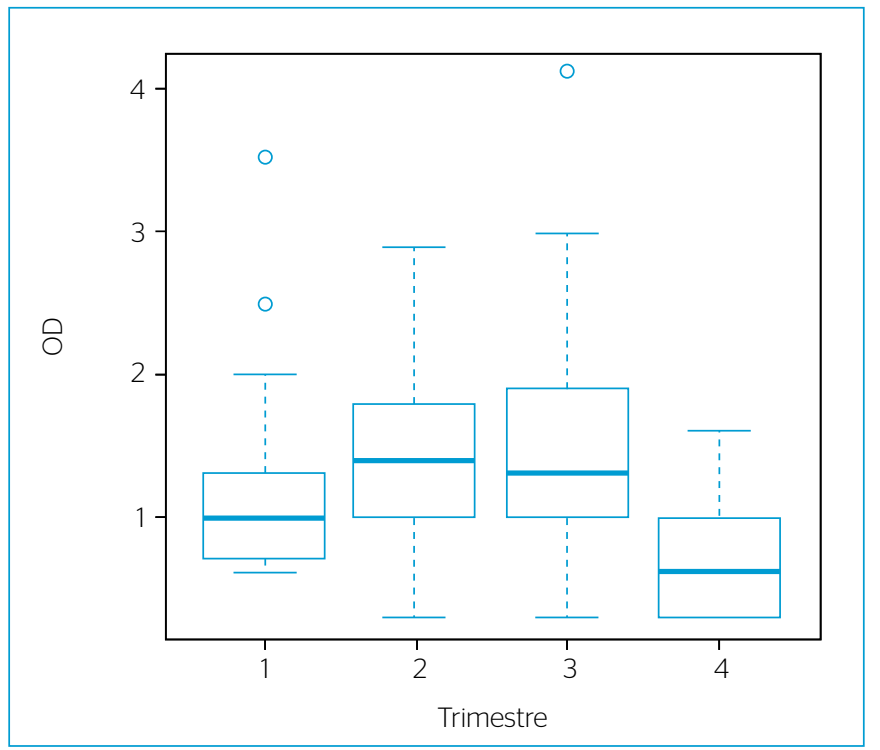

Figura 7 - Boxplot dos valores de oxigênio dissolvido em cada trimestre de coleta. 
ferro, cobre, chumbo, zinco e cádmio das tubulações, o que dificulta o tratamento das águas. Na região, o valor mediano de $\mathrm{pH}$ é $6,0 \pm 0,3$.
A série correspondente à distribuição do $\mathrm{pH}$ é estacionária (p do teste $\mathrm{ADF}=0,001)$ e o modelo mais parcimonioso foi o SARIMA $(0,0,1)$

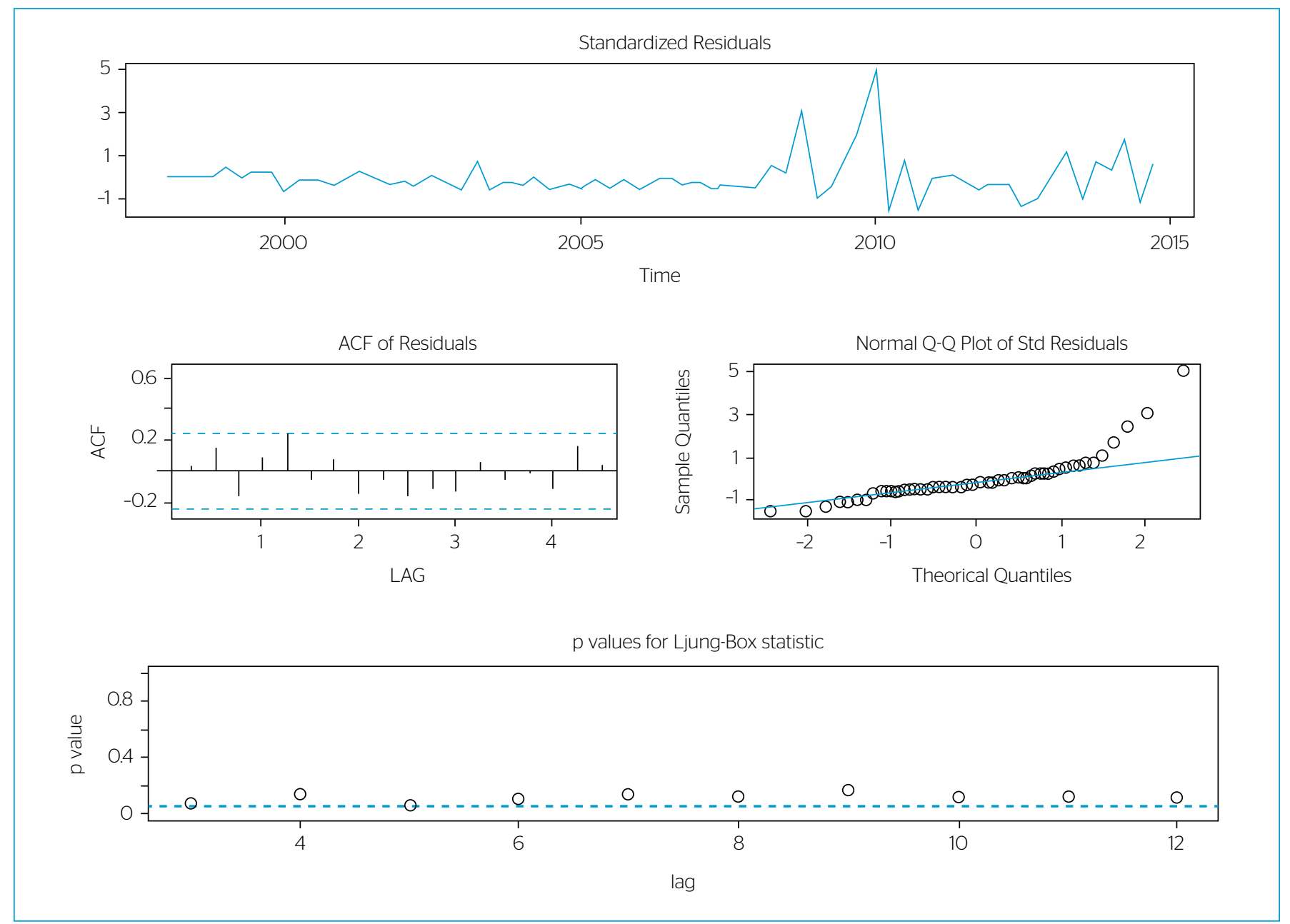

Figura 8 - Validação do modelo de ferro - modelo sazonal autorregressivo integrado de média móvel $(1,0,0)(1,0,0)$.

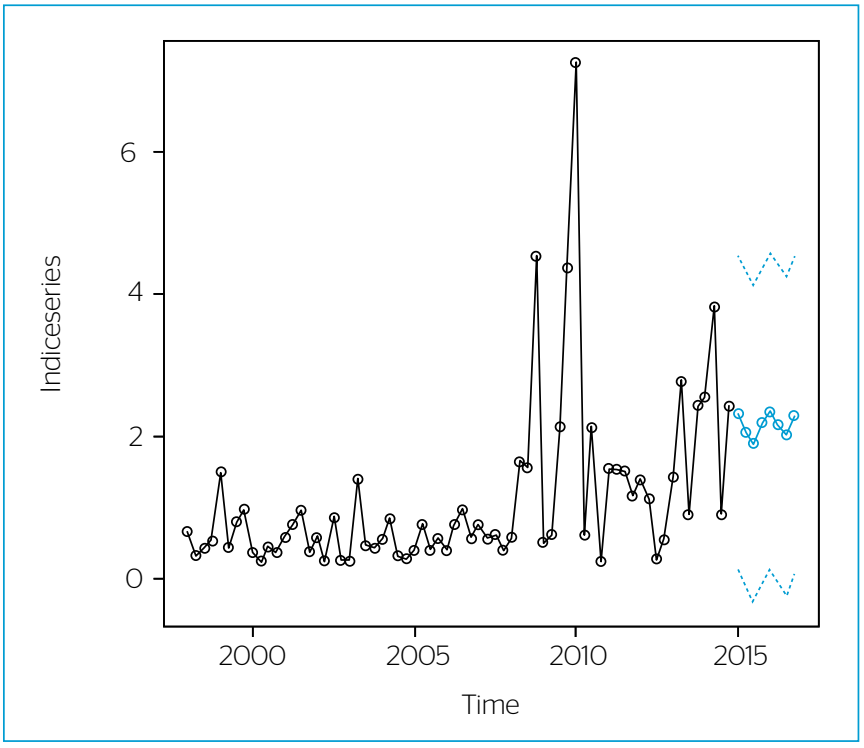

Figura 9 - Previsão pelo método de séries temporais.

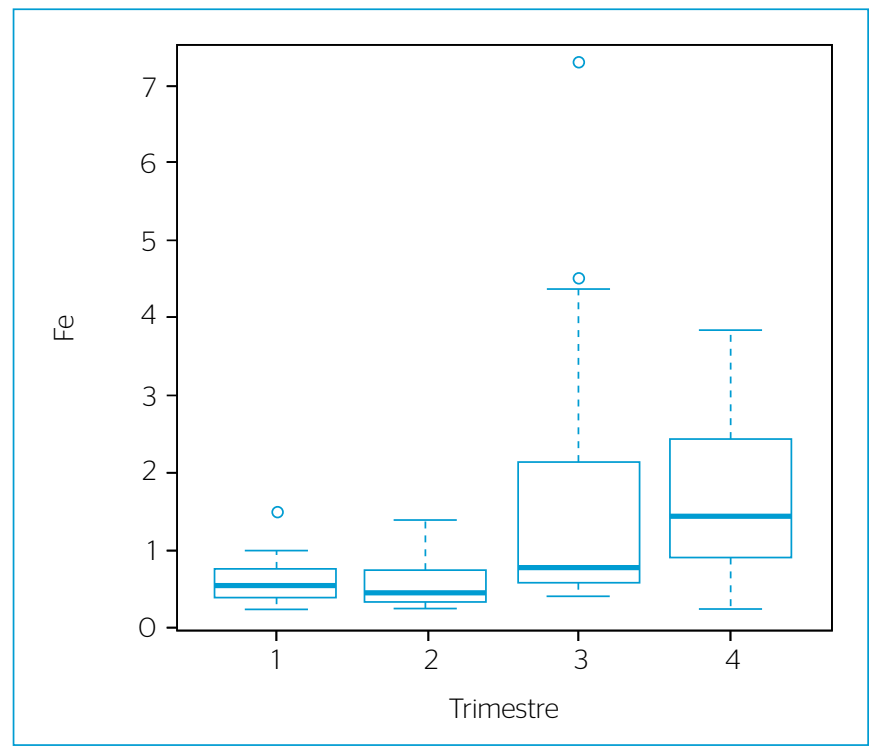

Figura 10 - Boxplot dos valores de ferro em cada trimestre de coleta. 
$(2,0,1)_{4}$. A validação do modelo está apresentada na Figura 11 e mostra que ele é adequado, ou seja, eficiente na estimação e com os resíduos normalmente distribuídos e não correlacionados.

A Figura 12 exibe os resultados de $\mathrm{pH}$ ao longo dos anos no ponto de monitoramento BG057 e a previsão para os dois anos seguintes. O pH apresenta dispersão em seus valores entre 2000 e 2012. Por ser um indicador generalista da estabilidade do ambiente aquático, a maior amplitude entre as medições mostra como o ambiente aquático passou a sofrer oscilações que provavelmente levarão a um stress maior da biota desses reservatórios.

É importante lembrar que o ponto BG057 está próximo à pilha de enxofre. As não conformidades no local são no sentido de maior acidez, o que sugere a necessidade de averiguar a influência dos efluentes industriais no $\mathrm{pH}$ do córrego Gameleiras. Segundo a previsão da série, não há tendência de melhora na qualidade das águas do córrego.

Os valores de $\mathrm{pH}$, segundo o teste Kruskal-Wallis, não variaram significativamente entre os trimestres $(\mathrm{p}=0,461)$, mas sim entre os anos

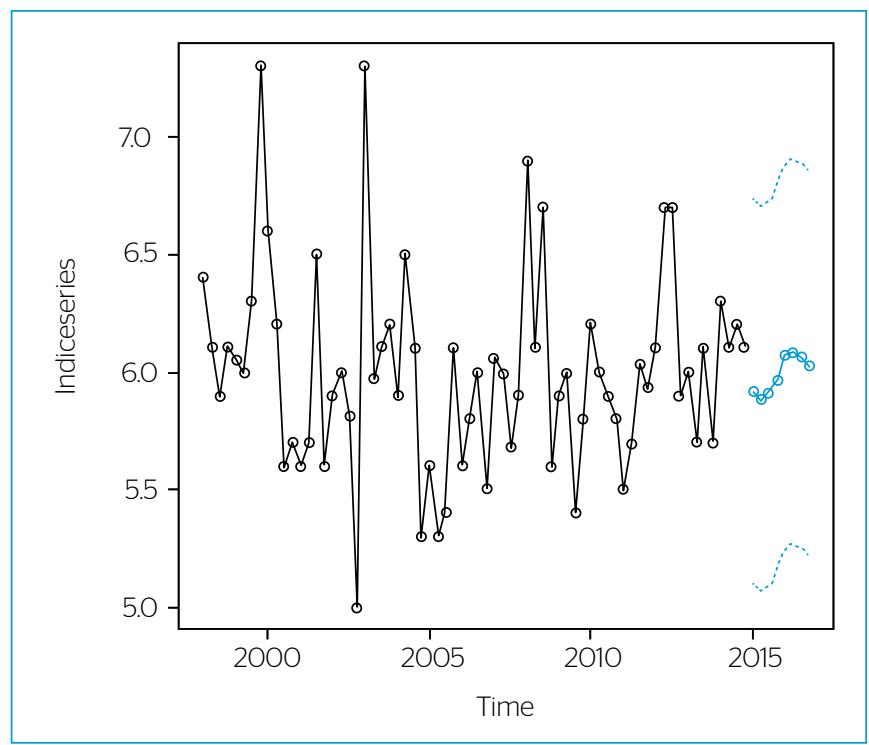

Figura 12 - Previsão pelo método de séries temporais.

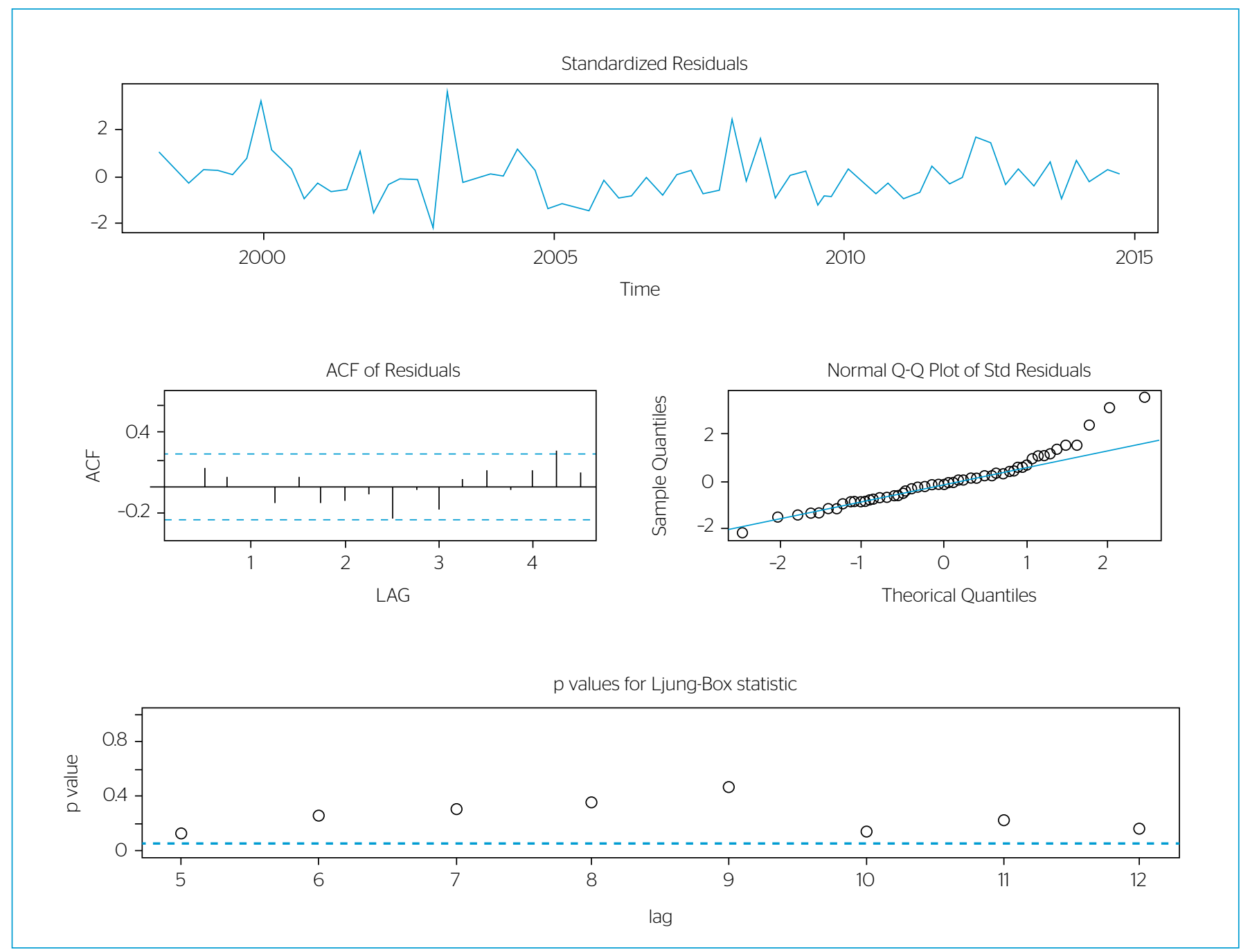

Figura 11 - Validação do modelo de ferro - modelo sazonal autorregressivo integrado de média móvel $(1,0,0)(1,0,0)$. 
$(\mathrm{p}=0,004)$. Os resultados de $\mathrm{pH}$ em cada ano de monitoramento está apresentado na Figura 13 e confirma as oscilações de seus valores ao longo de todo o período.

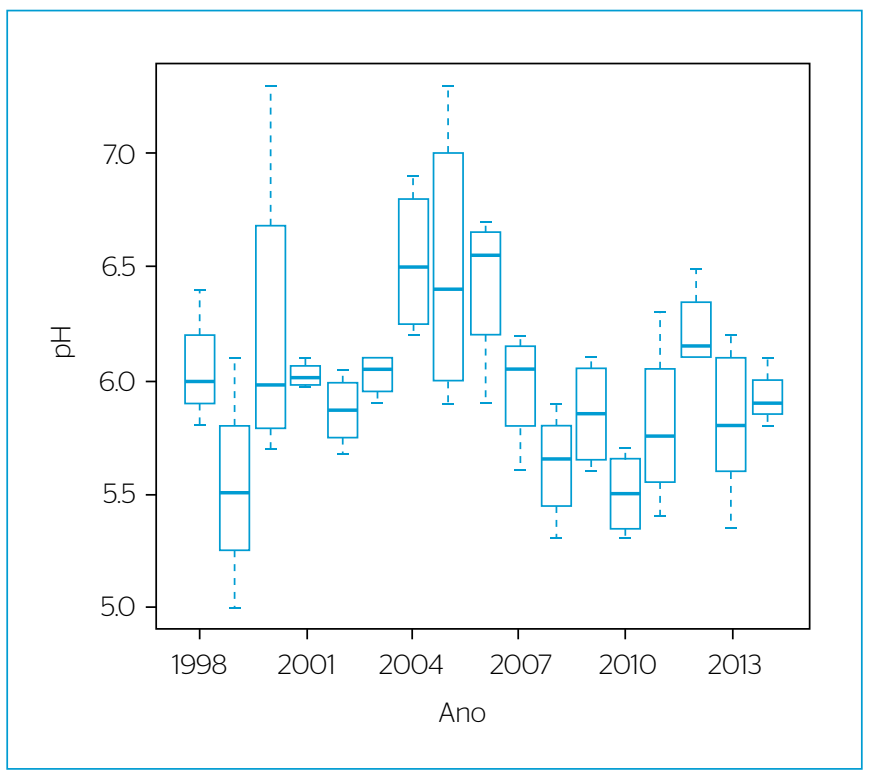

Figura 13 - Boxplot dos valores de pH em cada ano de coleta.

\section{Fósforo total}

O fósforo é um elemento essencial aos seres vivos por participar do armazenamento de energia, da estruturação da membrana celular, da transferência de informação genética e do metabolismo celular (ESTEVES, 2011). O fósforo é originado naturalmente da dissolução de compostos do solo e da decomposição da matéria orgânica. O aporte antropogênico é oriundo dos despejos domésticos e industriais, além de detergentes, excrementos de animais e fertilizantes (VON SPERLING, 2007). A presença de fósforo nos corpos d'água desencadeia o desenvolvimento de algas ou de plantas aquáticas indesejáveis, principalmente em reservatórios ou corpos de água parada, podendo conduzir ao processo de eutrofização (CETESB, 2015).

O VMP para a variável em questão, segundo a legislação, é 0,02 mg.L $\mathrm{L}^{-1}$, e no BG057 todas as coletas apresentaram concentração acima desse limite, com mediana igual a $1 \mathrm{mg} \cdot \mathrm{L}^{-1}$ e desvio absoluto mediano de $0,9 \mathrm{mg} \cdot \mathrm{L}^{-1}$.

Na região, o fósforo tem três principais origens: esgotos doméstico e pecuário, agricultura e efluente industrial com ênfase em indústria de fertilizantes.

A série temporal do fósforo, segundo o teste $\mathrm{ADF}$, era estacionária $(\mathrm{p}=0,009)$ e apresentou bom ajuste e adequabilidade dos resíduos (Figura 14) para o modelo SARIMA $(0,0,2)(0,0,2)_{4}$.

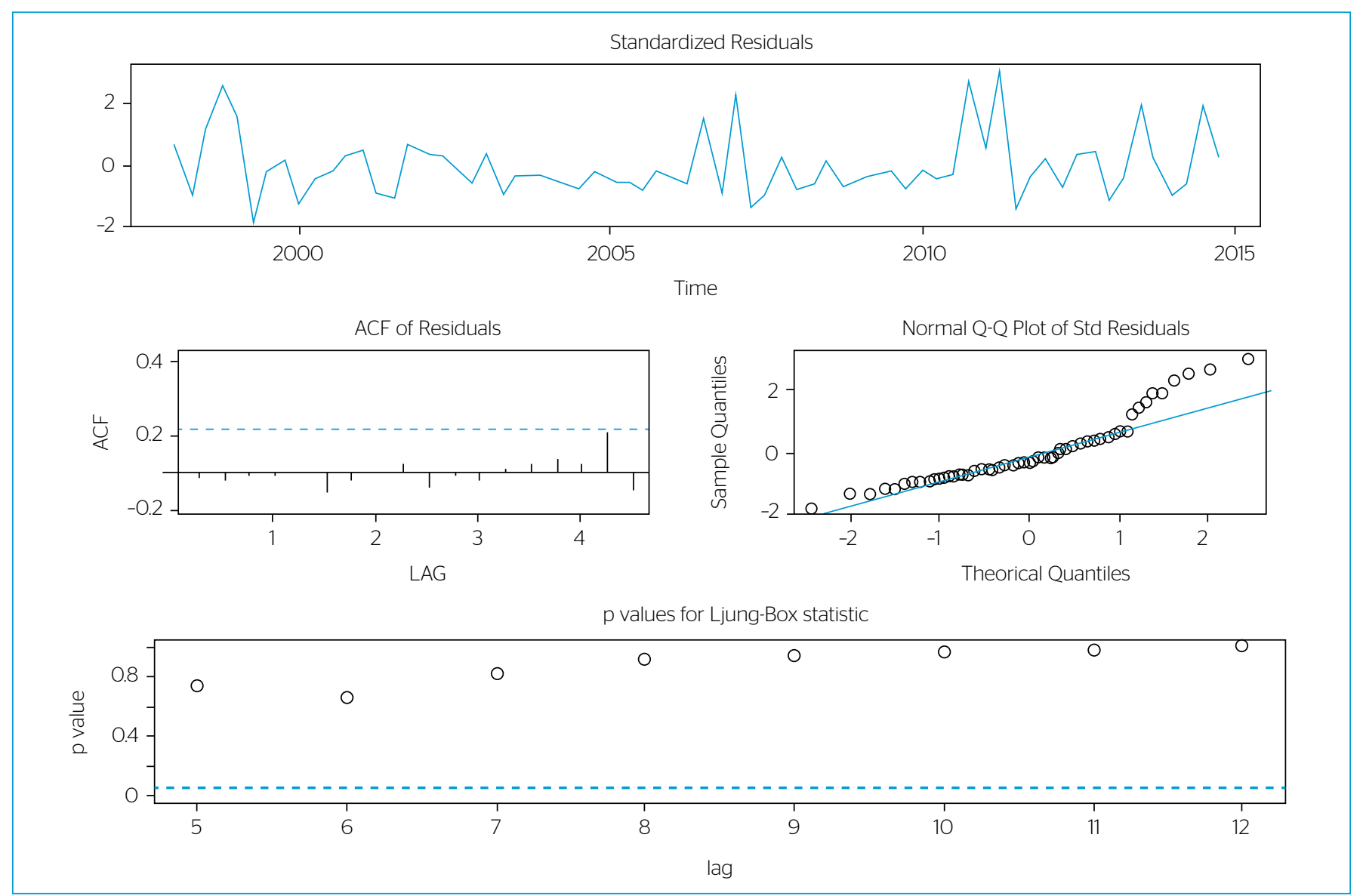

Figura 14 - Validação do modelo de fósforo - modelo sazonal autorregressivo integrado de média móvel MA(0,0,2)(0,0,2) . 
A distribuição do fósforo ao longo dos anos e a sua respectiva previsão para os dois anos seguintes estão apresentados na Figura 15. Ocorreram acentuados aumentos da contaminação por fósforo nos períodos de expansão da cultura da cana-de-açúcar, entre os anos de 2005 e 2007, e depois em 2012. Pode-se dizer que a cultura de cana-de-açúcar contribui para a conservação do solo, com exceção da sua fase inicial de preparo, em que a terra permanece exposta por período prolongado, facilitando a incidência de processos erosivos intensos, na forma de ravinas ou sulcos, o que pode comprometer a qualidade das águas na região (PISSARRA; POLITANO; FERRAUDO, 2004; GUIMARÃES, 2010).

É necessário citar novamente a presença de indústria de fertilizantes nas proximidades do ponto BG057. Coelho et al. (2000, p. 17) relatam que "o córrego Gameleiras recebe todo o resíduo da indústria Fosfértil, e tem apresentado um aumento significativo no aporte de nitrogênio e fósforo para o reservatório". A previsão realizada em relação ao fósforo mostrou tendência de piora na qualidade das águas.

O teste Kruskal-Wallis indicou que as concentrações do fósforo variaram com o trimestre $(\mathrm{p}=0,007)$ e com o ano $(\mathrm{p}=0,005)$. Os boxplots apresentados nas Figuras 16 e 17 ilustram a constatação do teste e permitem concluir que a qualidade das águas é melhor no período de seca (março a outubro) devido a menor lixiviação.

\section{Cana-de-açúcar e fosfogesso}

Na região em estudo, há de se chamar maior atenção para as usinas de cana-de-açúcar e para a indústria de processamento de fosfato.

O ponto de coleta BG057 fica situado próximo à indústria de fertilizante, na qual estão localizadas pilhas de fosfogesso e enxofre (Figura 18).

Os valores medidos e previstos de fósforo e $\mathrm{pH}$ sugerem a influência das pilhas de fosfogesso e enxofre nas proximidades do ponto de coleta

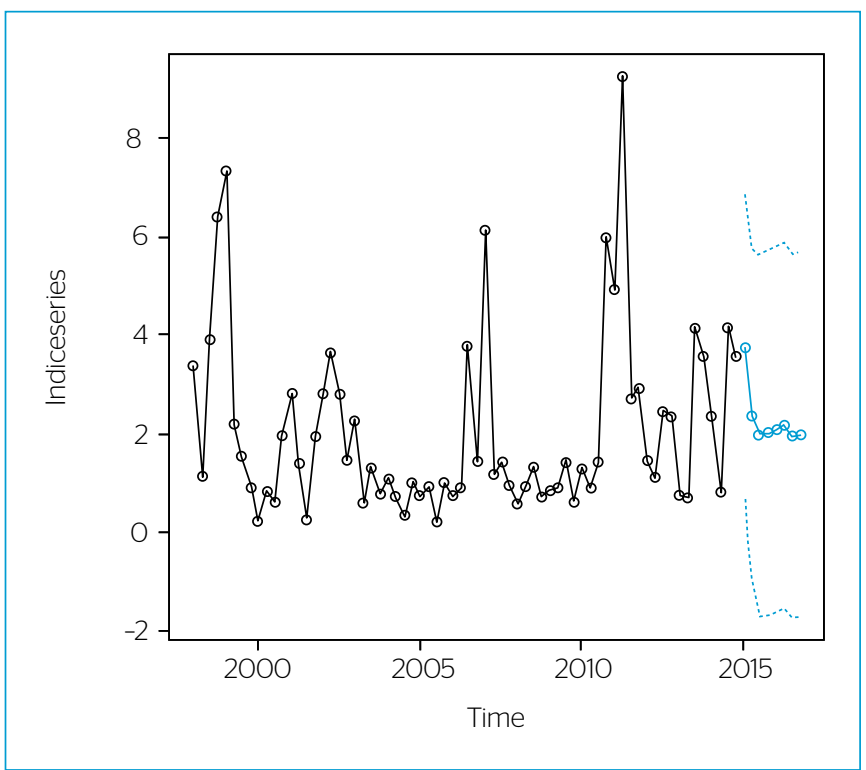

Figura 15 - Previsão pelo método de séries temporais. estudado. O fósfogesso encontrado nas proximidades do BG057 contém elementos radioativos (NISTI et al., 2015); entretanto, não é feita rotineiramente a análise desses elementos nas águas do córrego Gameleiras.

$\mathrm{O}^{226} \mathrm{Ra} \mathrm{e}^{228} \mathrm{Ra}$ são coprecipitados com o cálcio na forma de $\mathrm{RaCaSO}_{4}$, e o VMP desses elementos na água, segundo o Ministério da Saúde, é até 1.000 vezes menor do que o valor encontrado no fosfogesso (JACOMINO et al., 2009). A possibilidade de lixiviação e presença de radionuclídeos nas águas é grande (EL-DIDAMONY et al., 2013).

De acordo com Ometto (2005), o ciclo de vida da cadeia produtiva da cana-de-açúcar envolve o preparo do solo, o cultivo agrícola, o transporte interno, o processo industrial, a reutilização dos resíduos e dos

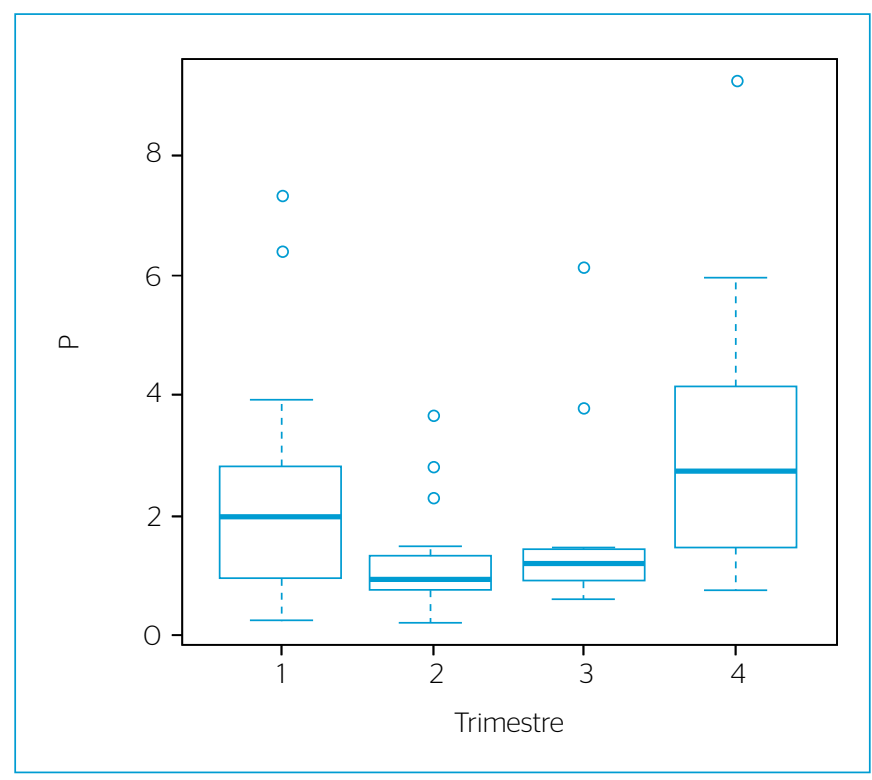

Figura 16 - Boxplot dos valores de fósforo em cada trimestre de coleta.

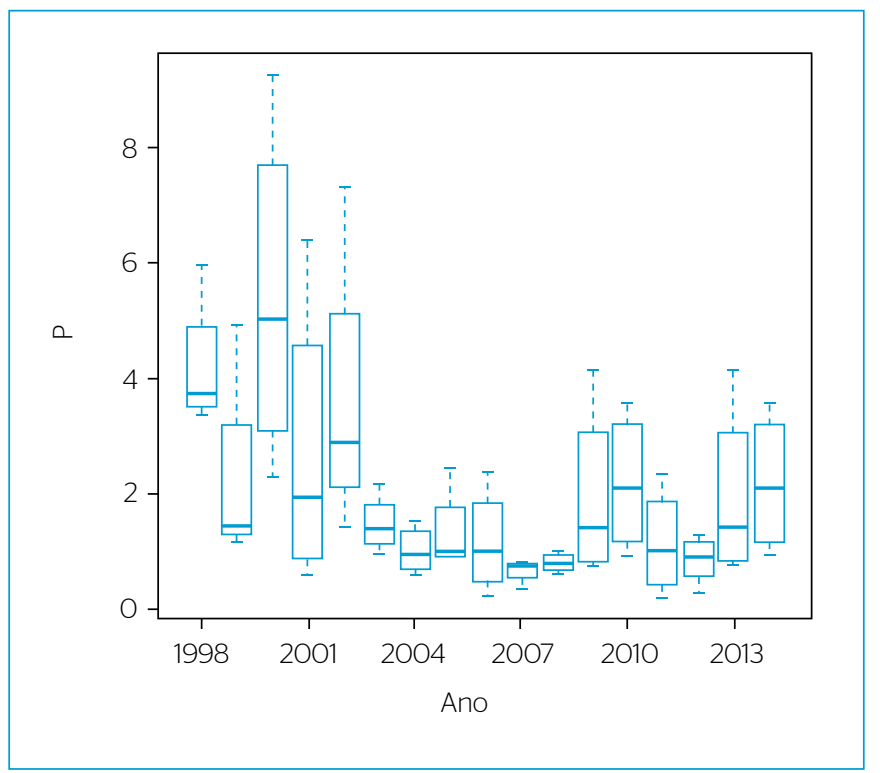

Figura 17 - Boxplot dos valores de $\mathrm{pH}$ em cada ano de coleta. 
efluentes industriais, a geração de vapor e energia elétrica, a armazenagem e distribuição e a utilização do álcool etílico hidratado combustível e/ou do açúcar. Na região em estudo, os dados do Canasat (2015) (Figuras 19 e 20) revelam um grande salto nos plantios de cana entre 2004 e 2005. A partir de 2005, tanto em São Paulo quanto em Minas
Gerais, ocorreu uma aceleração no crescimento da área cultivada com cana. Em 2012, houve nova expansão da área plantada.

Piacente (2005) levanta diversos impactos ambientais do cultivo da cana-de-açúcar, entre os quais destacam-se: redução da biodiversidade, causada pelo desmatamento e pela implantação de monocultura;
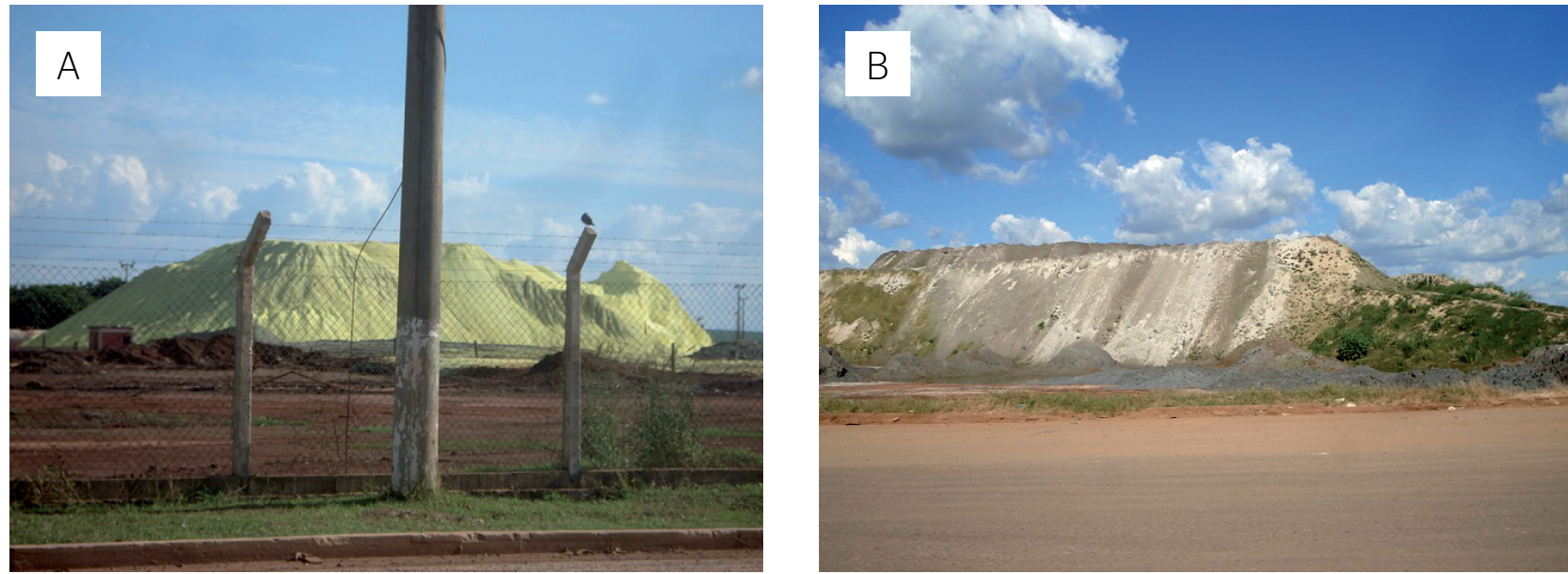

Figura 18 - Pilhas de enxofre e fosfogesso em indústria de fertilizantes nas proximidades do ponto BG057.

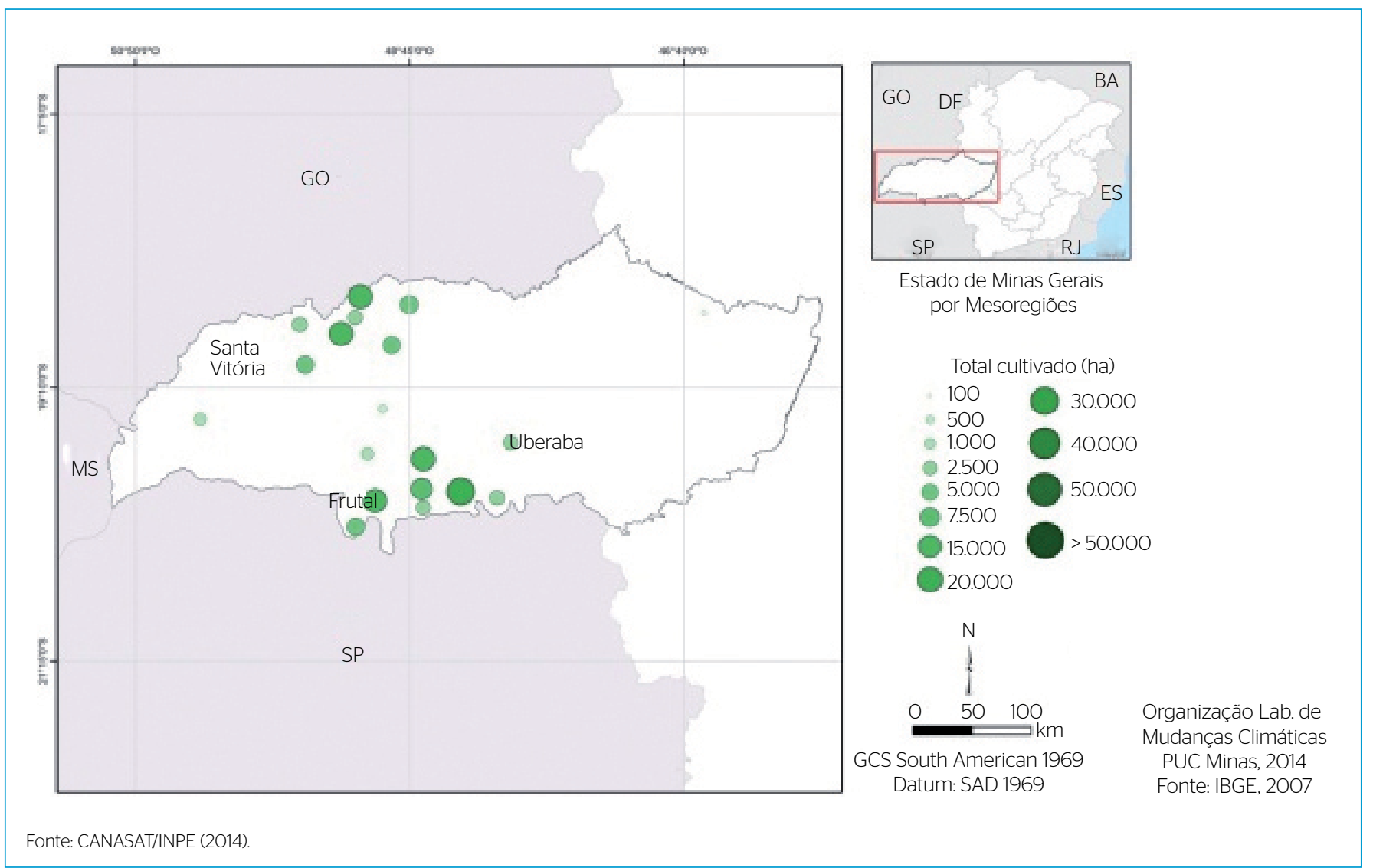

Figura 19 - Total cultivado da cana-de-açúcar no Estado (SAFRA: 2003-2004). 


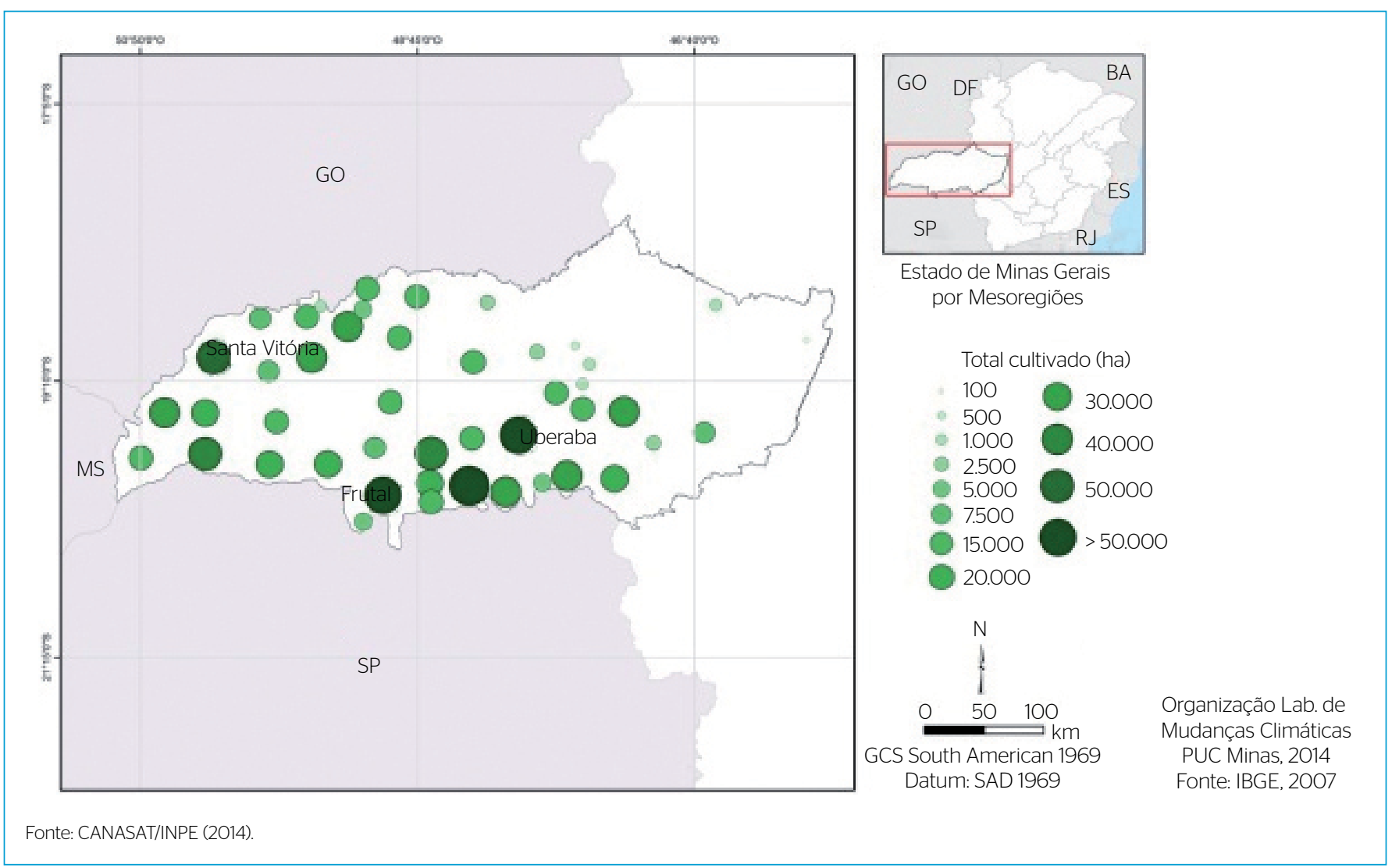

Figura 20 - Total cultivado da cana-de-açúcar no Estado (SAFRA: 2013-2014).

contaminação das águas superficiais e subterrâneas e do solo, por meio da prática de adubação química, corretivos minerais e aplicação de herbicidas e defensivos agrícolas; assoreamento de corpos d'água, devido à erosão do solo em áreas de reforma; emissão de fuligem e gases de efeito estufa na queima, ao ar livre, de palha durante o período de colheita; $\mathrm{e}$ danos à flora e à fauna causados por incêndios descontrolados.

\section{CONCLUSÕES}

Nesta pesquisa, foi feita a análise sazonal e temporal das águas do córrego Gameleiras, na estação BG057.

No reservatório de Volta Grande, onde está situada a área de estudo, foram constatados períodos de eutrofização e "bloom" de algas, motivados inclusive pelo aumento das taxas de fósforo que o reservatório vem recebendo por meio de seus tributários.

Em 17 anos de monitoramento, nenhuma das variáveis avaliadas apresentou resultados melhores, ou sequer perspectiva de melhora, em relação à qualidade das águas. Isso sugere que, durante esse período, nenhuma ação efetiva foi realizada. Ficou comprovado que as ações antrópicas estão colocando em risco as águas na região e que, em todo o já referido período de monitoramento, nenhuma medida efetiva foi tomada para reverter tal quadro.
O estudo do uso e ocupação do solo mostrou que as mais prováveis causas de contaminação na região são: indústria nas proximidades, esgoto doméstico e da agropecuária e preparo do solo para expansão da cultura da cana-de-açúcar.

Tratamento de efluentes industriais e domésticos, reflorestamento da mata ciliar, construção de barreiras de retenção durante o manuseio do solo e outras medidas de tecnologia simples e conhecidas poderiam ser adotadas para melhorar as condições atuais. Logo, as ações usuais de melhoria de condições das águas poderiam ser adotadas para a reversão do quadro.

As desconformidades de fósforo sugerem contaminação por efluentes industriais. Devido à presença do fosfogesso, que contém material radioativo, é sugerida a inclusão de um ponto de coleta em local mais próximo à pilha de rejeito industrial e também medições de radioatividade nesse novo ponto, bem como no BG057. As medições de radioatividade devem ser realizadas por tempo suficiente para conclusões: um período mínimo de dois anos.

O ponto BG057 é monitorado pelo IGAM e em, seus relatórios, é citado como um dos de pior qualidade de águas do Estado de Minas Gerais.

As ações antrópicas estão colocando em risco as águas de Minas Gerais. Foi constatado que o ponto de coleta reconhecidamente com 
péssima qualidade de águas tende a continuar ou piorar essa qualidade, inclusive porque é evidente a influência de tais águas no reservatório de Volta Grande.
A metodologia utilizada neste trabalho mostrou-se eficiente. Além disso, o programa $\mathrm{R}$ e seus pacotes, além de gratuitos, são eficazes e de fácil utilização.

\section{REFERÊNCIAS}

BOX, G.E.P.; JENKINS, G.W.; REINSEL, G.C. (2008) Time series analysis: forecasting and control. Hoboken: John Wiley \& Sons, Inc.

BRAGA, B. \& HESPANHOL, I. (2005). Introdução à engenharia ambiental: o desafio do desenvolvimento sustentável. 2 ed. São Paulo: Pearson Prentice Hall. 318 p.

CANASAT. (2015) Monitoramento de cana-de-açucar via satélite. Disponível em: <http://www.dsr.inpe.br/laf/canasat/>. Acesso em: 15 set. 2015.

CARVALHO, M.D. \& ROLLA, M.E. (2008) CEMIG geração e transmissão: relatório de projeto e apresentação de trabalho sobre o Reservatório de Volta Grande. Disponível em: CEMIG - Companhia Energética de Minas Gerais S.A. Acesso em: O4 set. 2015.

CASTILLO J.; PÉREZ-LÓPEZ R.; SARMIENTO A.M.; NIETO J.M. (2O12) Evaluation of organic substrates to enhance the sulfate-reducing activity in phosphogypsum. Science of the Total Environment, v. 439, p.106-113.

COELHO, R.M.P.; GRECO, M.K.B.; BICALHO, C.S.; ROLLA, M.E. (2000) Balanço de massa de fósforo, evolução do grau de eutrofização, biomassa e crescimento de eichhornia crassipes no reservatório de volta grande. Relatório Final do Projeto CRA-FAPEMIG 72042/96. Disponível em: <www. ecologia.icb.ufmg.br/ rpcoelho/art_pdf/rf_cra72042.pdf>. Acesso em: 10 set. 2015.

COGHLAN, A. (2014) A little book of R for time series. Disponível em: $<$ https://media.readthedocs.org/pdf/a-little-book-of-r-for-time-series/ latest/a-little-book-of-r-for-time-series.pdf>. Acesso em: 10 set. 2015.

COMPANHIA AMBIENTAL DO ESTADO DE SÃO PAULO - CETESB. (2015) Significado ambiental das variáveis de qualidade das águas e dos sedimentos e metodologias analíticas de amostragem. In Qualidade das águas interiores no estado de São Paulo. Disponível em: <http://cetesb.sp.gov.br/aguas-interiores/wp-content/uploads/ sites/32/2013/11/variaveis.pdf>. Acesso em: 05 set. 2015.

EL-DIDAMONY, H.; GADO, H.S.; AWWAD, N.S.; FAWZY, M.M.; ATTALLAH, M.F. (2013) Treatment of phosphogypsum waste produced from phosphate ore processing. Journal of Hazardous Materials, v. 244, p. 596-602.

ESTEVES, F.A. (2011) Fundamentos de Limnologia. 3 ed. Rio de Janeiro: Interciência. 826 p.

FILZMOSER, P. (2015) StatDA: Statistical Analysis for Environmental Data. R package version 1.6.9. Disponível em:
<http://cran.r-project.org/web/packages/StatDA/StatDA.pdf> Acesso em: 07 ago. 2015.

GUIMARÃES, E.N. (2010) Série relatórios metodológicos: PIB dos municípios. Rio de Janeiro: IBGE.

HYNDMAN, R.J. (2015) Forecast: forecasting functions for time series and linear models. R package version 6.1. Disponível em: <https://cran.r-project.org/web/packages/forecast/>. Acesso em: 07 ago. 2015.

INFOHIDRO. (2015) Sistema Estadual de Informações sobre Recursos Hídricos. Disponível em: <http://portalinfohidro.igam. mg.gov.br/seriehistorica>. Acesso em: 15 set. 2015.

INSTITUTO MINEIRO DE GESTÃO DAS ÁGUAS - IGAM. (2010) Monitoramento das águas superficiais na Bacia Grande: Relatório anual 2009. Belo Horizonte: IGAM. Disponível em: <http://www. igam.mg.gov.br/images/stories/rafael/relatorio-executivo-2010. pdf>. Acesso em: 15 set. 2015.

INSTITUTO NACIONAL DE METEOROLOGIA - INMET. (2O15) Dados históricos. Disponível em: <http://www.inmet.gov.br/portal/ index.php?r=bdmep/bdmep>. Acesso em: 15 set. 2015.

JACOMINO, V.M.F.; OLIVEIRA, K.A.P.; TADDEI, M.H.T.; SIQUEIRA, M.C.; CARNEIRO, M.E.D.P.; NASCIMENTO, M.R.L.; SILVA, D.F.; MELLO, JW.V. (2009) Conteúdo de radionuclídeos e metais pesados em amostras de fosfogesso, comparativamente ao de solos do cerrado. Revista Brasileira de Ciências do Solo, v. 33, n. 5, p. 1481-1488.

MINAS GERAIS. (2008) Conselho Estadual de Política Ambiental e de Recursos Hídricos COPAM/CERH-MG. Deliberação Normativa Conjunta no 01, maio de 2008. Disponível em: <http://www.feam.br/ index.php? Itemid=109\&id=83\&option=com_content\&task=view $>$. Acesso em: 22 jul. 2015

MORETTIN, P.A. \& TOLOI, C.M.C (2006) Análise de séries temporais. 2 ed. São Paulo: Edgard Blucher. 535 p.

NISTI, M.B.; SAUEIA, C.R.; MALHEIRO, L.H.; GROPPO, G.H.; MAZZILLI, B.P. (2015) Lixiviation of natural radionuclides and heavy metals in tropical soils amended with phosphogypsum. Journal of Environmental Radioactivity, v. 144, p.120-126.

OMETTO, A.R. (2005) Avaliação do ciclo de vida do álcool etílico hidratado combustivel pelos métodos EDIP, Exergia e Emergia. Tese (Doutorado em Engenharia Hidráulica e Saneamento) Escola de Engenharia de São Caros, Universidade de São Paulo, São Carlos, SP. 
PACHECO, C.H.A. (2009) Dinâmica espacial e temporal de variáveis limnológicas e sua influência sobre as cianobactérias em um reservatório eutrofizado: açude Acarape do Meio-CE. Dissertação (Mestrado em Engenharia Civil e Ambiental) - Universidade Federal de Campina Grande, Campina Grande, PB.

PIACENTE, F.J. (2005) Agroindústria canavieira e o sistema de gestão ambiental: o caso das usinas localizadas nas Bacias Hidrográficas dos Rios Piracicaba, Capivari e Jundiaí. Dissertação (Mestrado em Desenvolvimento Econômico) - Universidade Estadual de Campinas, Campinas, SP.

PISSARRA, T.C.T.; POLITANO, W.; FERRAUDO, A.S (2004). Avaliação de características morfométricas na relação solo-superfície da Bacia Hidrográfica do Córrego Rico, Jaboticabal (SP). Revista Brasileira de Ciência do Solo, v. 28, n. 2, p. 297-305.

QIU, D. (2015) aTSA: Alternative time series analysis. R package version 3.1.2. Disponível em: <https://cran.r-project.org/web/packages/aTSA/>. Acesso em: 07 ago. 2015.

R CORE TEAM. (2015) R: A language and environment for statistical computing. The R Project for Statistical Computing. Disponível em: <http://www.R-project.org/>. Acesso em: O1 mai. 2015.

REIMANN, C.; FILZMOSER, P.; GARRETT R.; DUTTER R. (2008) Statistical data analysis explained: applied environmental statistics with R. 1 ed, New York: John Wiley \& Sons. 362 p.

RONG, Y. (2011) Practical environmental statistics and data analysis. Glendale: ILM Publications. 269 p.
SHAPIRO, S.S. \& WILK, M.B. (1965) An analysis of variance test for normality (complete samples). Biometrika, v. 52, n. 3/4, p. 591-611.

SHESKIN, D.J. (2011) Handbook of parametric and nonparametric statistical procedures. 5 ed. Boca Raton: Chapman \& Hall. 1926 p.

TODOROV, V. (2013) Package rrcov. Scalable robust estimators with high breakdown point. R package version.3-2. Disponível em: <http://cran.r-project.org/web/packages/rrcov/rrcov.pdf>. Acesso em: 07 ago. 2015.

TODOROV, V. \& FILZMOSER, P. (2009) An object oriented framework for robust multivariate analysis. Journal of Statistical Software, v. 32, p. 1-47.

TRAPLETTI, A. (2015) tseries: time series analysis and computational finance. R package version 0.10-34. Disponível em: <https://cran.r-project.org/web/packages/tseries/>. Acesso em: 07 ago. 2015.

TUNDISI, J.G.; MATSUMURA-TUNDISI, T.; TUNDISI, J.E.M. (2008) Reservoirs and human well being: new challenges for evaluating impacts and benefits in the neotropics. Brazilian Journal of Biology, v. 68, n. 4, p.1133-1135.

UBERABA. (2014) Distrito Industrial III. Disponível em: <http://www. uberaba.mg.gov.br/portal/conteudo,1030>. Acesso em: 28 jun. 2014.

VON SPERLING, M. (2007) Estudos e modelagem da qualidade das águas de rios. Belo Horizonte: Departamento de Engenharia Sanitária e Ambiental da UFMG. 588 p. 